\title{
A Small, Wearable, Stretchable Electrocardiogram and Physical Activity Monitoring System
}

\author{
Alex Chun Kit Chan, \\ Hiroyuki Hamada, Hiroki \\ Fujiwara, Sayaka Okochi, \\ Kohei Higuchi \\ Maenaka Human-sensing Fusion \\ Project, ERATO, JST \\ 2167 Shosha, Himeji, Hyogo \\ 671-2280, Japan \\ alexckchan@eratokm.jp
}

\author{
Atsushi Kajiya \\ Nippon Mektron, Ltd. \\ 1-12-15, Shiba-Daimon, Minato-ku, \\ Tokyo, 105-8585, Japan \\ kajiya_119@mektron.co.jp
}

\author{
Takayuki Fujita, \\ Kazusuke Maenaka \\ Graduate School of Engineering, \\ University of Hyogo \\ 2167 Shosha, Himeji, \\ Hyogo 671-2280, Japan \\ maenaka@eng.u-hyogo.ac.jp
}

\begin{abstract}
Recently, many research studies and development projects focus on wearable sensor systems for applications such as human activity recognition or monitoring, biomedical clothing, health monitoring and medical care. In general, this kind of wearable system should be small-sized, lightweight, low-power, comfortable and non-invasive for the user. In this study, we present a prototype of electrocardiogram (ECG) and physical activity monitoring system using a low-power consumption 315 $\mathrm{MHz}$ RF transceiver module and stretchable wiring used to increase the snugness of the system.
\end{abstract}

Currently, most of the wearable systems use Bluetooth or ZigBee as the wireless interface. In general, when Bluetooth or ZigBee are active, they consume more than $15 \mathrm{~mA}$ current during RF communication. Since the battery is the main power source for these kinds of wearable systems, reducing the power consumption during RF communication can significantly increase the battery lifetime.

Therefore, the authors have realized a low-power consumption, small-sized and lightweight $315 \mathrm{MHz}$ transceiver module powered by a $3.3 \mathrm{~V}$ supply voltage. The module consumes $1 \mathrm{~mA}$ and $2 \mathrm{~mA}$ for the transmission and receiving modes respectively.

The entire system is composed of three blocks - the main block, RF block and the power block. The interconnection of each block is implemented with stretchable wiring to enhance the tensility and flexibility. Therefore, the user's comfort and mobility should be improved.

Without the antenna, the system can be fabricated with an area of $110 \times 30 \mathrm{~mm}^{2}$. The main block is comprised of an ECG amplifier circuit, a 3-axes accelerometer, an altimeter sensor, a humidity sensor, a temperature sensor and an $8051 \mathrm{MCU}$. The low-power $315 \mathrm{MHz}$ transceiver module is equipped in the RF block. The power block is composed of a typical coin-sized rechargeable lithium-ion battery $(3.7 \mathrm{~V}, 75 \mathrm{mAh})$ and a regulator with charging

Permission to make digital or hard copies of all or part of this work for personal or classroom use is granted without fee provided that copies are not made or distributed for profit or commercial advantage and that copies bear this notice and the full citation on the first page. To copy otherwise, or republish, to post on servers or to redistribute to lists, requires prior specific permission and/or a fee.

BodyNets 2012, Oslo, Norway, 24-26 September 2012. circuit. The block diagram and image of the proposed system are shown in Figs. 1 and 2, respectively.

The $8051 \mathrm{MCU}$ is used to control the entire operation of the system. The ECG and accelerometer data are sampled at $125 \mathrm{~Hz}$. The altimeter, humidity, temperature and battery voltage data are sampled at $8 \mathrm{~Hz}$. The data are packed into a packet and transferred to the $315 \mathrm{MHz}$ RF module using a Universal Asynchronous Receiver Transmitter (UART). Then, the sensed information and ECG are displayed in graphical form on the PC in real time.

During continuous transmission of the sensed information, the MCU, sensors and ECG circuitry are always active. Under this condition, the entire system only consumes $15.5 \mathrm{~mA}$ of current. Thus, for a $75 \mathrm{mAh}$ battery, the proposed system can operate for more than 4 hours. In the future, further reduction of current consumption can be achieved through reduction of the wireless communication period, putting the MCU, RF module and sensors in standby mode, and decreasing the frequency of MCU clock.

\section{Categories and Subject Descriptors}

J.3 [Computer Applications]: Life and Medical Sciences Health, Medical information systems.

\section{General Terms}

Design, Experimentation.

\section{Keywords}

ECG Monitoring, Small-sized, Stretchable, Wearable, Low power consumption, $315 \mathrm{MHz}$ RF transceiver.

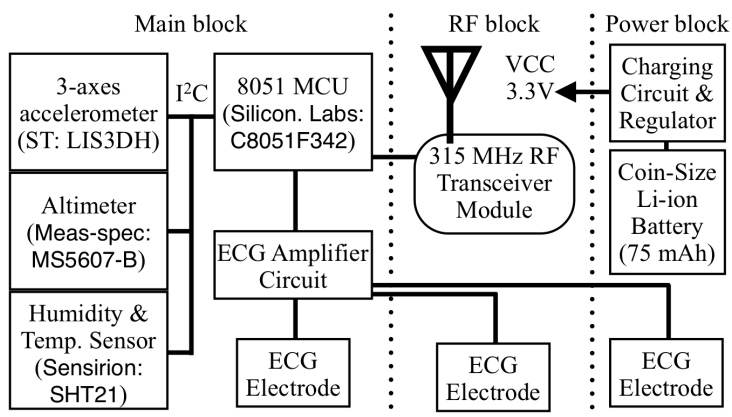

Figure 1. Block diagram of the system. 


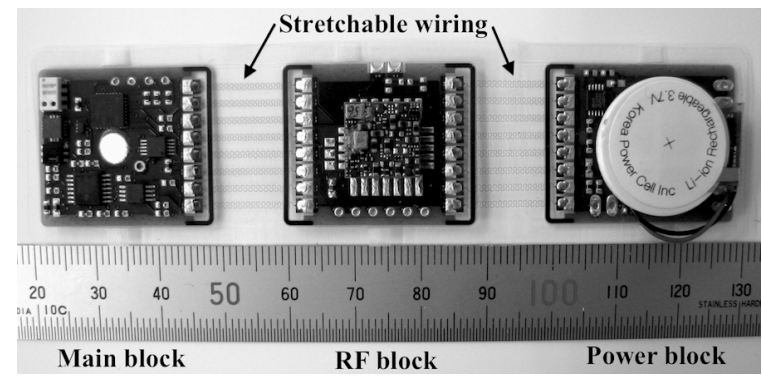

Figure 2. Image of the system. 